letters

\section{TO THE EDITOR}

Please submit letters for the

Editor's consideration within three weeks of receipt of the Journal.

Letters should ideally be limited to 350 words, and can be submitted on disk or sent by e-mail to: Clinicalmedicine@rcplondon.ac.uk.

\section{Withdrawing nutrition and hydration}

Editor - I wonder if I detect a semantic 'trick', played on us by the legal profession, in Keith Andrew's helpful paper on withdrawing nutrition and hydration (Clin Med July/August 2003, pp 342-5).

Recent attempts to define 'best interests' have been very unsatisfactory and I agree that the issue of nutrition and hydration is a complicated one. However, to say 'where the treatment is not benefiting the patient the treatment is not in the patient's best interest' may intend to convey no more than that the proposed treatment is of no apparent value to him and is unlikely to advance his immediate 'well-being'. From an ethical viewpoint, there would be no obligation for such measures to be offered or accepted.

Unfortunately, the legal profession takes the phrase 'not in his best interests' to mean not just 'of no value to him' but also to carry the connotation that the treatment is actually contrary to his best interests and therefore deleterious or 'harmful to him'. In other words, by a trick of language, they will argue from a statement that something is of little or no value to the patient, but harmless, to the position that it is positively contrary to, and thus harmful to, his best interests and therefore not only need not but must not be given.

IAN JESSIMAN Retired General Practitioner

\section{In response}

Editor - Dr Jessiman raises a point arising from the case of Tony Bland, in which Keith Andrews was a witness and has voiced strongly held objections since (Clin Med July/August 2003, pp 342-5).

The issue in the case was whether an incompetent person's best interests could ever include the withholding or withdrawal of life-sustaining treatment. The House of Lords reasoned that it was futile to continue Bland's treatment since he had no hope of recovery. It could not therefore be in his best interests to continue. Thus it would be lawful to withdraw the life support (in that particular case, hydration and nutrition) and indeed it might be unlawful to continue. The judges distinguished this from a doctor actively and intentionally bringing about the death of a patient. The law, they said, drew a distinction between acts and omissions: withdrawal was an omission. Withdrawal could only be unlawful if the omission amounted to a breach of the doctor's duty of care to the patient. The Lords held that it did not.

In the view of Dr Jessiman therefore, the treatment is harmful to the patient in the sense that his interests are harmed and not his corporeal body as such. His body is not harmed by artificial nutrition: it was sustained by it. In English law doing something that is not in a person's best interests is not harmless because those interests are significant and valuable. They are valued equally with other interests, such as in being hydrated and ventilated simpliciter.

Dr Jessiman seems to me to be correct in averring that the 'legal profession takes the phrase "not in his best interests" to mean not just "of no value to him" but also ... "harmful to him". However, I do not think he is correct to argue that the harm is of no significance. It is an acceptance that continued treatment may be deleterious, even when compared to death.

DEREK MORGAN

Professor of Health Care Law and Jurisprudence Cardiff University of Wales

\section{Diagnosing acute headache}

Editor - We found the piece by Dr Davenport on Diagnosing Acute Headache (Clin Med 2004 March/April pp 108-12) very informative. However, Figure 1 appears to suggest that patients presenting with headache should be referred to a neurologist from the emergency department prior to excluding both meningitis and sub-arachnoid haemorrhage.

We would automatically look for these in our department and initiate the appropriate treatment prior to referral for a specialist opinion. We feel that a practice of referring all acute headaches directly to the neurologists would incur unnecessary delays in the intervention for these two conditions.

MAISSE FARHAN Specialist Registrar

JONATHAN HUTT

Pre-registration House Officer

Accident and Emergency, Charing Cross Hospital, London

\section{In response}

Many patients presenting to the emergency department (ED) with headache may be dealt with adequately by ED staff, without requiring a referral to a neurologist immediately. However, any patient with a true acute onset headache will almost certainly require admission for further investigations, and I believe that these patients should be admitted to a neurosciences unit, rather than a general medical or ED observation ward.

Of course, antibiotics for suspected meningitis should never be delayed, and I would expect the ED staff to have already administered these and any other potentially life-saving treatment prior to referral. But once the ED team have identified that the problem is an acute onset headache, they should be calling their neurologist (assuming they have one). A useful analogy might be the management of acute chest pain; the diagnosis and immediate treatment of an acute myocardial infarction may be initiated in the ED, followed by rapid and seamless transfer to the care of a cardiologist. As a general rule, I believe that outcomes are better if patients are treated by specialists (by which I mean neurologists, cardiologists etc, rather than superspecialist headache doctors), and there is evidence to support this assertion (eg stroke units for stroke patients rather than general medical wards). 